\title{
Scientific contributions in the field of Transport and Supply Chain Management
}

\author{
Author: \\ Stephen Kruger ${ }^{1}$ \\ Affiliation: \\ ${ }^{1}$ Faculty of Management, \\ University of Johannesburg, \\ South Africa \\ Correspondence to: \\ Stephen Kruger \\ Email: \\ stephenk@uj.ac.za \\ Postal address: \\ Department Transport and \\ Supply Chain Management, \\ D Ring 7, Corner of \\ Kingsway and University \\ Road, Auklandpark 2006, \\ Johannesburg, South Africa \\ How to cite this article: \\ Kruger, S., 2013, 'Scientific \\ contributions in the field of \\ Transport and Supply Chain \\ Management', Journal of \\ Transport and Supply Chain \\ Management 7(1), Art. 128, \\ 2 pages. http://dx.doi.org/ \\ 10.4102/jtscm.v7i1.128 \\ Copyright: \\ (C) 2013. The Authors. \\ Licensee: AOSIS \\ OpenJournals. This work \\ is licensed under the \\ Creative Commons \\ Attribution License.
}

Read online:
The Department of Transport and Supply Chain Management at the University of Johannesburg proudly presents to you Volume 7 of the Journal of Transport and Supply Chain Management (JTSCM), an accredited publication unique to South Africa.

\section{Background}

In 2005, the JTSCM was launched. It was initially managed by the Department; the editor was one of the academic staff. From the beginning it was clear that a need within the transport and supply chain academic community was being met, as the journal grew consistently. In the 2012 edition, 18 articles were published. Contributions to the JTSCM, excluding South Africa, have included articles from India, Zimbabwe, Kenya, Croatia, Malysia, Australia, Germany, Tanzania, Uganda, Ethiopia, Namibia, the UK and USA in the past.

In order to enhance the stature of the JTSCM, an independent editor was appointed in 2012. The decision was also taken to outsource the administrative activities to AOSIS, a professional management company that manages a range of academic journals. This arrangement commenced at the beginning of 2013. From 2012, the journal also became open-access. It publishes articles on a continuous basis as soon as the review and approval processes are completed.

\section{Fields of study}

The JTSCM continues to serve as an independent publication for scientific contributions in the field of transportation and supply chain management, including: logistics; operations management; purchasing management; distribution management; warehousing management; transportation (all modes); production planning; and other related fields.

The journal continues to seek to align the academic and practical aspects of transportation, logistics and supply chain management and to disseminate information on important issues and recent developments in these fields. It also seeks to provide practical insight and guidance to the members of these industry sectors as they seek to implement processes and systems that will provide them with strategic and competitive advantages in their respective markets.

All academics in the fields of transport management, transport economics, logistics, supply chain management and other related fields with a strong flavour of transport management or supply chain management (such as general management, change management and strategic management) are invited to participate. Academics from the engineering field, such as transport engineering, are also invited to submit articles to this journal.

The JTSCM has gained in popularity over the past six years. Each year articles from authors on various matters relating to the fields of transportation and supply chain management are presented. Thank you to all of the authors that have worked so hard to make this an interesting and varied publication. On-going gratitude must also be expressed to the editorial panel and reviewers, without whose dedication the annual publication of the JTSCM would not be possible.

This edition of the journal features articles that have been reviewed and revised by national and international panel members who are acknowledged scholars and authors. They add so much value to the body of knowledge for academics, practitioners and policy makers in transport, logistics and supply chain management. These various research topics will help to contribute to the development of these fields, as our readers gain a deeper understanding of the issues in these sectors. This year the total contribution of high-quality articles is 22 . 


\section{A word on the importance of Transport Management as a topic}

Throughout the world transport is undergoing major changes with major infrastructure investments in ports, airports, railway systems and pipelines. The world economy, in general, is still depressed following the 2008 financial crisis. However, investments in transportation systems are crucial to ensure lower supply chain costs and more competitive economies.

It is evident that rail systems are going through a 'renaissance' period with renewed investments to better meet the needs of rail freight and passenger customers. These developments are welcomed in an era of sustained high crude oil prices, the focus on greener logistics systems and a general over-reliance on road transport for medium to long haul freight transportation. The movement of freight from road to rail will be a gradual process, as concomitant investments will have to be made in intermodal facilities and other infrastructure in order to change over from a road based biasedness to rail transport.

Public transport systems are also attracting more attention throughout the whole world. Massive investments (and re- investments) are being made in urban rail systems, metro systems and bus rapid transport (BRT). In South Africa, for instance, one of the largest investments in the country's history is currently underway, with more than 8000 passenger railway coaches being replaced to modernise the urban rail system over the next 20 years.

The development of BRT has been of particular interest to developing countries due to lower fixed costs compared to conventional rail systems and the ability to 'retrofit' such systems in a compact urban environment. With some of the latest technology, these systems have the ability to carry large volumes of passengers, which in some instances is comparable to light and heavy rail systems.

It is evident that the transport sector throughout the world is currently readying itself for the next global growth phase, which ought to result in lower costs of trade and improved public transport systems. At the same time, much attention is being paid to lower the carbon footprint of this sector on the world's climate by introducing new legislative requirements to compel the sector to become more environmentally friendly. 